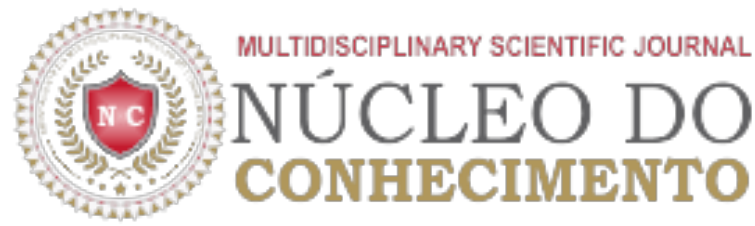

\section{Caracterização Socioeconômica e Ambiental em uma Comunidade Costeira da Região Amazônica, Pará - Brasil}

\author{
OLIVEIRA, Euzébio de ${ }^{[1]}$
}

OLIVEIRA, Euzébio de. Caracterização socioeconômica e ambiental em uma comunidade costeira da região amazônica, Pará - Brasil. Revista Científica Multidisciplinar Núcleo do Conhecimento. Ano 01, Ed. 07, Vol. 04, pp. 21-34, Julho de 2016. ISSN:2448-0959

\section{RESUMO}

Este estudo foi realizado em Acarajó, uma comunidade agro-pesqueira integrante da RESEX Marinha Caeté-Taperaçu, localizada na Planície Costeira Bragantina, nordeste do Estado do Pará (Brasil). O objetivo deste estudo foI avaliar os aspectos sociais, econômicos e os fatores de degradação ambiental dessa comunidade. Para realização deste trabalho foram utilizadas metodologias baseadas em entrevistas, aplicação de questionários, observação direta e mensuração dos potenciais fatores de degradação ambiental. Em relação aos aspectos socioeconômicos foi observado que Acarajó é uma das comunidades com maior número de habitantes, localizada na área da RESEX, possuindo em sua maioria pessoas jovens, com baixa escolaridade e com baixa renda média mensal. Na comunidade faltam melhores oportunidades de trabalho e os serviços e infra-estruturas disponíveis à população são escassos ou inexistentes. Estes fatores contribuem com que o Índice de Condição de Vida e Moradia alcancem valores muito baixos, quando comparados com o mínimo aceitável. Em relação aos aspectos ambientais, essa comunidade apresenta sérios problemas decorrentes da falta de saneamento básico (presença de muito lixo, falta de água tratada, problemas de saúde, etc.), bem como em relação à degradação dos recursos naturais (desmatamento acelerado da vegetação de mangue, redução dos recursos pesqueiros e degradação do solo). Por fim, propostas de medidas de gestão costeira integrada foram apresentadas, visando contribuir com a melhoria da qualidade socioambiental da área estudada.

Palavras chaves: Caracterização. Socioeconômica. Meio ambiente. Comunidade Costeira.

\section{INTRODUÇÃO}

As zonas costeiras sempre foram locais de grande atrativo para as populações humanas, devido principalmente à disponibilidade e abundância de recursos naturais, e a grandes empreendimentos 
turísticos, industriais, imobiliários, entre outros. Em decorrência deste fato, cerca de $60 \%$ dos grandes centros urbanos estão localizados nesta região, fato que repercute em sérios conflitos de caráter socioambiental (CHI et al., 2001; LIAO et al., 2003; KULLENBERG, 2001; BILLÉ; MERMET, 2002).

No Brasil, nas últimas décadas, o rápido crescimento populacional nestas regiões vem resultando diversos problemas de caráter socioambiental (Alheiros, 1995; Diegues, 1999). Neste contexto, o nordeste do Estado do Pará é uma das regiões mais povoadas da costa norte do país, e consequentemente, uma das mais degradadas da região (SOUZA-FILHO, 2001; SILVA et al., 2006; PEREIRA et al., 2006b; ROSA et al., 2006; PEREIRA et al., 2007).

Com a finalidade de preservar o ambiente, através do uso sustentável dos recursos naturais, bem como de proteger os meios de vida e a cultura das populações tradicionais ali existentes, no ano de 2005, sobre Decreto Lei do Governo Federal, quatro Reservas Extrativistas Marinhas foram criadas neste setor paraense (MMA, 2005). Entre estas RESEX destaca-se a Reserva Extrativista Marinha Caeté-Taperaçu, na qual está inserida a comunidade agro-pesqueira de Acarajó (HENRIQUE, 2005).

Com o objetivo de contribuir com a elaboração de um plano de manejo para esta RESEX, buscou-se conhecer a dinâmica sócio-econômica e ambiental de uma das mais povoadas comunidades inseridas nesta unidade de conservação. Para alcançar este objetivo, um estudo sobre o perfil sócio-econômico dos moradores da comunidade, os tipos de uso e ocupação territorial local, bem como a caracterização e/ou a mensuração dos principais fatores potenciais de degradação ambiental que ocorrem nessa área foi realizado, a fim de contribuir com medidas de gestão integrada, buscando o desenvolvimento sócioeconômico sustentável das comunidades urbanas situadas na Reserva Extrativista Marinha CaetéTaperaçu.

\section{MATERIAL E MÉTODO}

\section{ÁREA DE ESTUDO}

Acarajó está localizada a, cerca de, $7 \mathrm{~km}$ da sede do município de Bragança e possui uma área de, aproximadamente, 100,55 ha. Suas delimitações geográficas são: ao norte com a comunidade de Bacuriteua, ao sul com a comunidade do Abacateiro, a leste com o rio Caeté (que se desemboca no oceano Atlântico), e a oeste com as comunidades do Maçarico e Taperaçu Campos (ADAMS; MACEDO, 2001) (figura 1). 


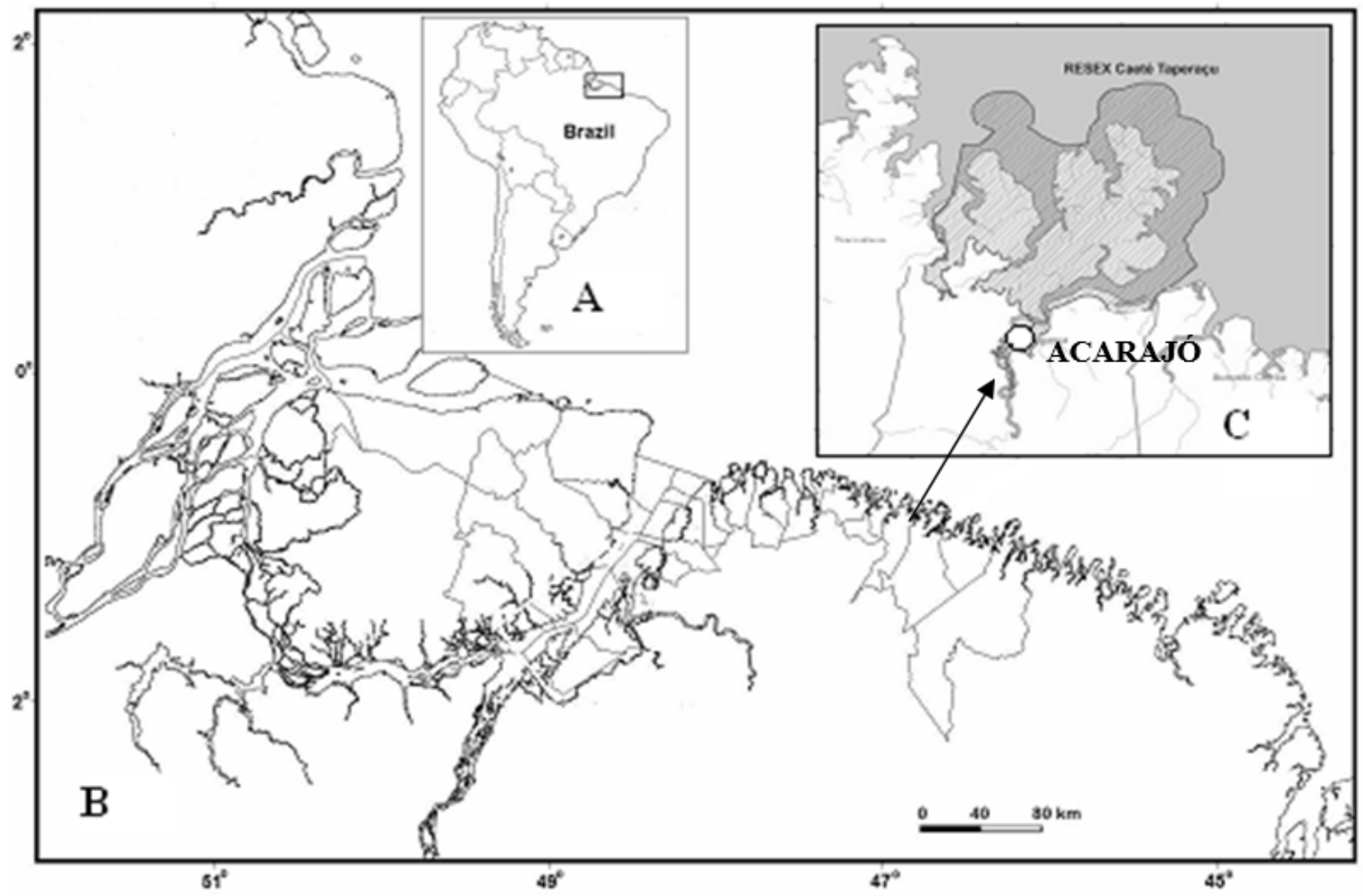

Figura 1. Localização da área de estudo. (A) Brasil, (B) zona costeira amazônica brasileira, (C) RESEX Marinha Caeté-Taperaçu - localização da comunidade de Acarajó.

A Planície Costeira Bragantina é caracterizada pela ocorrência de manguezais que ocupam 95\% de toda a área costeira da mesma, sendo os bosques de mangue compostos basicamente pelas espécies de Rhizophora mangle, Laguncularia racemosa e Avicennia germinans, sendo a $R$. mangle a espécie dominante (BERGER et al., 1999; KRAUSE et al. 2001; PROISY et al., 2003).

O clima da região é quente e úmido, com uma variação bem definida pela presença de um período seco e outro chuvoso. As temperaturas médias anuais oscilam entre 20,4 e $32,8{ }^{\circ} \mathrm{C}$, e a umidade relativa do ar entre 77 e 91\%, (INMET, 1992; MARTORANO et al., 1993).

Acarajó é uma das mais povoadas comunidades agro-pesqueiras integrantes da Reserva Extrativista Marinha Caeté-Taperaçu, sendo formada por vários ecossistemas locais, como manguezal, mata de terra firme e floresta tropical. A ocupação territorial de Acarajó é outro fator que a distingue em relação às demais comunidades agro-pesqueiras da região, uma vez que, a ocupação ocorreu às margens da PA 458, formando dois aglomerados locais, denominados de Acarajózinho e Acarajó-Grande; e outro mais para o interior da área da comunidade, em direção ao estuário do rio Caeté, denominado de Acarajó (SANTOS, 1996).

\section{METODOLOGIA}


Questionários semi-estruturados, entrevistas, observações diretas e mensuração dos principais fatores de degradação ambiental foram realizados entre os meses de maio/2006 a fevereiro/2007, para caracterizar as condições sócio-ambientais da comunidade em estudo.

Questionários semi-estruturados compostos por três blocos de perguntas (perfil sócio-econômico, condição de vida e moradia e opinião e percepção dos moradores sobre os problemas ambientais) foram aplicados em $100 \%$ das residências, durante os meses de julho e agosto de 2006. O perfil sócioeconômico dos moradores levantou informações sobre o sexo, idade, ocupação/profissão, renda, estado civil e grau de escolaridade.

Para determinar a condição de vida e moradia dos habitantes de cada residência foi necessário calcular o Índice de Condições de Vida e Moradia (ICV-MO), de acordo com metodologia descrita por Costa (2004), seguindo o padrão utilizado pelo Índice de Desenvolvimento Sócio-Econômico, desenvolvido pela Fundação de Economia e Estatística (IDESE/FEE), através da fórmula $($ ICV-MO = (p1 x IAF) + (p2 x ISP) + (p3 x IP)), sendo o IAF, o Índice dos Aspectos Físicos da Moradia; o ISP, o Índice dos Serviços Públicos à disposição da comunidade; e o IP, o Índice da Situação da Propriedade.

Os tipos de infra-estrutura e serviços disponíveis para a comunidade (saúde, saneamento básico, educação, transporte, etc.) foram identificados por meio de observação direta, seguindo a metodologia de checklist aplicada por Junyent (1999) e Pereira et al. (2003), bem como através de entrevistas.

Os questionários destinados à opinião e percepção dos moradores sobre os problemas ambientais foram elaborados de acordo com os trabalhos de Morgan et al. (1993), Morgan et al. (1995) e Leatherman (1997) e adaptados à realidade local. Estes questionários foram aplicados a um membro de cada residência.

Após a opinião e percepção dos moradores a respeito dos problemas ambientais, bem como da observação direta a respeito da infra-estrutura e serviços disponíveis, e da condição ambiental da comunidade, metodologias específicas foram adotadas para mensurar/analisar alguns problemas ambientais apontados/detectados, como o acúmulo de lixo doméstico, a qualidade da água para consumo, o desmatamento e o uso do solo para agricultura. A metodologia aplicada segue abaixo:

(i) Produção de lixo doméstico: primeiramente foi analisado o destino dado ao lixo (coletado pela prefeitura, queimado, enterrado, jogado em terrenos baldios, campos, etc.) Em seguida, o trabalho de mensuração do lixo foi realizado por meio de duas amostragens, uma no final do mês de setembro e a outra no início do mês de novembro/2006, sendo cada amostragem representada pelo lixo produzido durante dois dias em $30 \%$ do total de casas da comunidade. Com base na média das duas amostragens foi estimada a produção de lixo mensal para $100 \%$ das residências da comunidade. Em cada amostra coletada o lixo orgânico (não reciclável) foi pesado separadamente do lixo inorgânico (reciclável), em seguida foram realizadas análises de variação de produção (início e final do mês). Para determinar a normalidade e a homogeneidade dos dados foram realizados os testes de Lilliefors (CONOVER, 1971) e Bartlett's (SOKAL; ROHLF, 1969), respectivamente, com auxílio do programa STATISTICA 6.0 (STATSOFT, 2001). Quando os dados não foram normais, utilizou-se transformações log $(x+1)$. Para os dados normais foi aplicada a análise de variância (ANOVA - one way), seguida pelo teste post-hoc de Fisher LSD. Porém quando as variâncias foram heterogêneas, foi aplicado o teste não-paramétrico de Mann-Whitney (Teste U). Em ambos os casos, as residências estudadas foram agrupadas em função do número de 
habitantes. Os trabalhos foram realizados baseando-se no manual Compromisso Empresarial para Reciclagem (1995), e no manual Gestão Integrada de Resíduos Sólidos na Amazônia (IBAM, 2005), sendo ambas as metodologias adaptadas à realidade local.

(ii) Qualidade da água: a coleta das amostras foi realizada durante o período seco (novembro/2006) e o período chuvoso (março/2007) em dois poços comunitários (água subterrânea extraída por poço tubular) da comunidade, sendo Poço 1 localizado a 46 46' 7. 416' ' W - $1^{\circ} 0^{\circ}$ '23.519' $\mathrm{S}$ e o Poço 2 na rodovia 458 a $46^{\circ} 46^{\prime} 26.852^{\prime}$ ' $\mathrm{W}-1^{\circ} 0^{\prime} 21.359^{\prime}$ ' S. Esses poços foram escolhidos por estarem entre os principais poços de abastecimento de água, atendendo um grande número de moradores da comunidade. Todas as análises físico-químicas foram realizadas no Laboratório de Oceanografia Costeira e Estuarina da UFPA, seguindo metodologias e/ou equipamentos específicos para cada componente estudado, sendo: a cor real e aparente analisada pelo equipamento Color of water HI 93727 Hanna Instruments, a turbidez pelo Microprocessor Turbidity Meter HI 93703 Hanna Instruments, o material em suspensão, pelo método de Strickland e Parsons (1972), o pH pelo Labmeter model pH2 - pHs-3B, a salinidade pelo Multianalizador Corning Checkmate II, o ferro dissolvido pelo Hardness \& Iron HI 93741 Hanna Instruments, os coliformes fecais e totais analisados a partir da técnica denominada de tubos múltiplos, seguindo as metodologias adotadas no American Public Health Association (2004), e a temperatura pelo Termômetro Incoterm L-168/04. Para a classificação da qualidade da água, os procedimentos foram realizados utilizando os parâmetros estabelecidos por resoluções específicas, de acordo com ANVISA (2004); CONAMA (1986, 2000, 2005) e SVS (2006).

(iii) Desmatamento (corte de árvores): foi mensurado com base nas respostas obtidas por entrevistas e pela aplicação de questionários com os moradores da comunidade, nos quais foram abordadas perguntas referentes ao extrativismo vegetal (corte de capoeira ou mangue), bem como, por meio de observação direta realizada durante o mês de agosto de 2006. A realização desse trabalho baseou-se no método de Greenwood (1973), que consiste na análise intensiva e variada da unidade/objeto de estudo.

(iv) Uso do solo para agricultura: por meio de aplicação de questionários e de observações diretas foram identificadas as áreas de cultivo, as práticas/tipos de agricultura e as técnicas de manejo do solo mais empregadas na comunidade em estudo, como a forma de aragem da terra, uso ou não de agrotóxicos e fertilizantes; derrubadas da capoeira e uso de queimadas. Esse trabalho foi realizado durante o mês de agosto de 2006, seguindo o método de Greenwood (1973).

\section{RESULTADOS E DISCUSSÃO}

\section{CARACTERÍSTICAS SÓCIO-ECONÔMICAS}

O censo demográfico em Acarajó mostrou que 358 famílias (em um total de 1696 indivíduos, ou seja, 4,74 pessoas por casa) habitam uma das maiores comunidades, em número de habitantes, da RESEX Caeté-Taperaçu. A maioria dos moradores é do sexo masculino (52\%), com idade compreendida entre 0 e 20 anos (55\%), constituídos por solteiros (62\%) e estudantes (36\%), com baixo grau de escolaridade, e $55 \%$ recebem menos de um salário mínimo por mês ( $\mathrm{R} \$ 380,00 *$ *)

Dentre as atividades de ocupação, a agricultura familiar aparece em primeiro lugar, sendo destinada à subsistência do grupo familiar. Todavia, a pesca, principalmente do caranguejo Ucides cordatus, é considerada uma das principais fontes de renda dos moradores locais (HENRIQUE, 2005). 
A baixa escolaridade, a pouca alternativa de empregos, a baixa renda e a predominância de famílias numerosas são fatores que contribuem para um baixo desenvolvimento sócio-econômico, nesta comunidade. Estes aspectos são semelhantes aos observados por Krause e Glaser (2003), Guimarães (2005), Silva et al., (2006), Pereira et al. (2006a) e Pereira et al. (2006b) que realizaram estudos semelhantes em outras comunidades agro-pesqueiras da região, fato que demonstra uma generalidade em relação às condições sócio-econômicas no litoral amazônico.

\section{CONDIÇÕES DE VIDA E MORADIA/INFRA-ESTRUTURA E SERVIÇOS}

Em relação ao Índice de Condição de Vida e Moradia ICV-MO, a comunidade de Acarajó apresenta um índice médio de 0,638, estando abaixo das condições mínimas aceitáveis para as comunidades costeiras, que é de 0,707, segundo o Índice de Desenvolvimento Sócio-Econômico criado pela Fundação de Economia e Estatística (IDESE/FEE). Das residências pesquisadas, apenas 29\% está acima do índice mínimo aceitável, apresentando uma média de 0,759 .

Este índice reflete, principalmente, as condições da construção das casas da comunidade (aspectos físicos e sanitários) e a falta de serviços e infra-estrutura disponíveis. Esta comunidade apresenta ainda um número considerável de casas de barro, coberta com folhas de palmeira seca, com chão de terra batida, não possuindo banheiro nem sistema de esgoto, nos quais algumas apresentam problemas relacionados ao abastecimento de água.

Com relação aos serviços públicos disponíveis foi observado que a comunidade não possui um sistema público de abastecimento de água potável, sendo o abastecimento realizado por meio de poços comunitários. A água é distribuída por meio de tubulação que vai até as residências, sendo que cada casa que adere a este sistema paga uma taxa de $\mathrm{R} \$ 10,00$ reais por mês (para a associação dos moradores) para utilização da água. Por outro lado, alguns moradores alegam que este "microssistema" de abastecimento de água não funciona regularmente.

Com relação ao ensino, Acarajó possui três escolas do ensino fundamental menor, desta forma os estudantes que necessitam continuar seus estudos precisam se deslocar até escolas do município de Bragança.

A comunidade não dispõe de nenhum posto de saúde, sendo que em casos leves, os comunitários recebem atendimento dos agentes comunitários que visitam regularmente as casas. Em casos de doenças mais graves ou de acidentes, os moradores buscam atendimento médico no posto de saúde localizado na comunidade vizinha de Bacuriteua, ou se dirigem aos postos de saúde e/ou hospitais do município de Bragança e Belém. Segundo os comunitários, as doenças de maior ocorrência são: malária, gripe, febre, diarréias, doenças de pele, dentre outras, sendo a malária a doença que mais afeta os moradores.

\section{OPINIÃO E PERCEPÇÃO SOCIOAMBIENTAL}

Com relação à opinião e à percepção dos moradores referente aos principais problemas ambientais que vêm ocorrendo na área da comunidade, os dados obtidos mostram que Acarajó enfrenta problemas relacionados às questões de saneamento básico (falta de um sistema de coleta de lixo, falta de água tratada e de sistema de esgoto), à degradação dos recursos naturais (sobre-pesca, desmatamento do manguezal, redução da fertilidade do solo, etc.), entre outros (tabela 1). 
Tabela 1. Principais problemas ambientais apontados pela população da Comunidade de Acarajó.

\begin{tabular}{lcc}
\hline \multicolumn{1}{c}{ Problemas Ambientais } & Freqüência de Respostas* & \% \\
\hline 1 - Decorrentes da falta de saneamento básico & & 96 \\
\hline Presença de lixo residencial na área de manguezal e rios & 344 & 70 \\
Presença de lixo na área residencial da Comunidade & 250 & 69 \\
Presença de lixo industrial na área de manguezal e rios & 247 & 37 \\
Doenças decorrentes de água contaminada e falta de sistema & & 132 \\
de esgoto & & 29 \\
Degradação do solo por acúmulo de lixo e esgoto & 104 & 87 \\
residencial/industrial & & 29 \\
\hline - Decorrentes da degradação dos recursos naturais & 311 & 24 \\
\hline Redução dos recursos pesqueiros e florestais & 104 & 23 \\
Desmatamento do manguezal & 86 & 10 \\
Pesca predatória/indiscriminada (peixes, caranguejo, etc.) & 82 & \\
Redução da produtividade/fertilidade do solo & & 6 \\
\hline 3 - Outros & 36 & 3 \\
\hline Decorrentes do aumento do turismo na região & & \\
Não existem problemas ambientais na área da & 11 & \\
comunidade & & \\
Não sabem responder as perguntas & & \\
\hline
\end{tabular}

* Freqüência de resposta para $\mathrm{N}=358$ (número de residências).

Problemas decorrentes do aumento do turismo na região bragantina também foram apontados pela comunidade, uma vez que a mesma está localizada na rodovia de acesso à praia de Ajuruteua (PA - 458), e entre o período de junho e julho o aumento de lixo ao longo da rodovia é um dos problemas que mais preocupa os moradores locais. Estes problemas se agravam em consequiência do descaso das autoridades locais que incentivam o turismo na região, sem antes realizar um planejamento racional sobre o uso e a ocupação territorial (GUIMARÃES, 2005).

Outro problema relacionado ao lixo, de acordo com os moradores, são os dejetos lançados pelas fábricas de pesca ao longo do Caeté e áreas adjacentes. De acordo com trabalhos realizados por Krause e Glaser (2003) e Silva et al. (2006), o problema com relação à produção do lixo, tanto residencial quanto industrial nas comunidades agro-pesqueiras da Planície Costeira Bragantina é uma questão grave, e deve ser tratada com seriedade, pois além dos danos causados ao ambiente, pode ocasionar problemas 
relacionados à saúde humana.

Segundo os moradores, algumas doenças como micoses, dengue, leptospirose, etc. estão relacionadas ao acúmulo de lixo na área da comunidade. Outras doenças que ocorrem na localidade e que estão relacionadas à falta de um sistema de saneamento básico, bem como ao desmatamento, também são consideradas preocupantes por parte da população como, por exemplo, a malária.

Por outro lado, a degradação dos recursos naturais e.g. a pesca indiscriminada e a derrubada de manguezal, também foram apontadas como problemas ambientais, de acordo com a percepção dos moradores. Segundo estes, a pesca indiscriminada e o desmatamento ocorrem como consequiência da escassa fiscalização pelos órgãos competentes, fato que vem comprometendo a pesca de subsistência de muitas famílias locais.

\section{PRODUÇÃO DE LIXO DOMÉSTICO}

Baseado nos dados obtidos por observação direta, bem como pelas informações repassadas pelos moradores é possível dizer que a comunidade de Acarajó vem enfrentando um sério problema em relação à produção de lixo. Os dados mostram que o sistema de coleta de lixo realizado pela prefeitura do município de Bragança é deficiente, pois não atende a toda comunidade, ocorre apenas três vezes por semana e apenas na rodovia Bragança-Ajuruteua. Em decorrência, muitos moradores jogam o lixo nos quintais de suas casas, ruas, estuário do Caeté, igarapés, manguezal, capoeiras, etc., provocando sérios problemas de caráter socioambiental, tais como contaminação do solo, recursos hídricos, saúde humana, estética, etc.

Em relação aos trabalhos de mensuração do lixo, os resultados mostraram que a produção média mensal de lixo doméstico da comunidade é de, aproximadamente, $5.029,375 \mathrm{~kg}$, com uma produção per capita mensal de aproximadamente $2,965 \mathrm{~kg}$, sendo $\pm 0,099 \mathrm{~kg} / \mathrm{dia}$ por pessoa. De acordo com o IBAM (2005), estes valores estão abaixo da média nacional, no qual a produção per capita é de 0,450 a $0,700 \mathrm{~kg} / \mathrm{dia}$. A produção de lixo orgânico não variou muito no decorrer do mês, mantendo-se praticamente inalterada em ambas as coletas, por outro lado o lixo inorgânico sofreu variações significativas $(F=6,59 ; \mathrm{p}=0,0090)$ em sua produção durante esse mesmo período, demonstrando valores mais elevados no início do mês estudado.

No entanto, os resíduos orgânicos foram os principais componentes do lixo analisado, representando 53\% do total, sendo composto basicamente por restos de comida e cascas de frutas (figura 3A). Estes dados são similares aos dados nacionais, os quais a matéria orgânica é o maior componente de lixo domiciliar produzido no país, representando em média, cerca de, 65\% do total (PEREIRA NETO, 1996; IBAM/MMA, 2005). Isto ocorre, provavelmente, devido ao fato desta comunidade ser mais "urbanizada" estando mais próxima da cidade de Bragança, e assim não reutiliza os resíduos orgânicos produzidos como fonte de alimento para criação de pequenos animais (pato, galinha, etc.), fato que ocorre na maioria das comunidades rurais da região. Por outro lado, do total de lixo inorgânico analisado, o plástico representa 43\%, seguido por papel/papelão com 27\%, vidro e lata $8 \%$, dentre outros (figura 3B).

Ao longo dos $25 \mathrm{~km}$ de rodovia da Planície Costeira Bragantina, não existe nenhum sistema de coleta de lixo, sendo este depositado no ambiente costeiro, constituindo assim, uma séria ameaça aos ecossistemas ali presentes (SOUZA-FILHO, 2001). Este não é um fato que vem ocorrendo somente na região 
bragantina, pois segundo Silva (2006), um dos maiores problemas da atualidade, que tem preocupado tanto os estudiosos da questão ambiental, quanto os planejadores e gestores públicos de várias partes do mundo, diz respeito ao problema do lixo produzido em áreas urbanas ou locais próximos às cidades, bem como, ao destino dos mesmos.

De acordo com Valente e Grossi (1999), no Brasil, o problema do lixo é muito complexo, pois em muitas cidades a maioria dos resíduos sólidos urbanos são depositados a céu aberto, nos rios, estuários, lagos, etc., fato que pode ocasionar contaminação do solo, dos recursos hídricos e gerar problemas relacionados à estética e à saúde humana.

A)

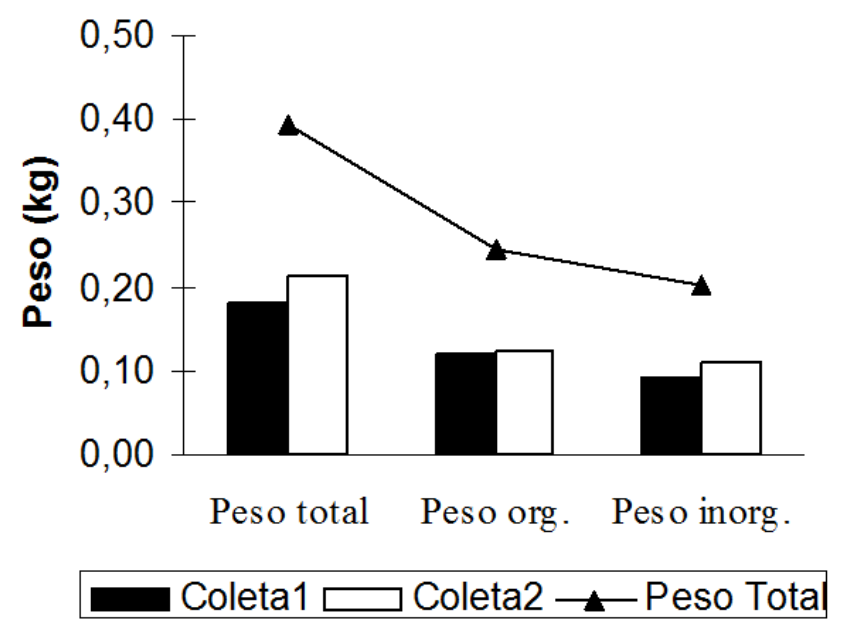

B)

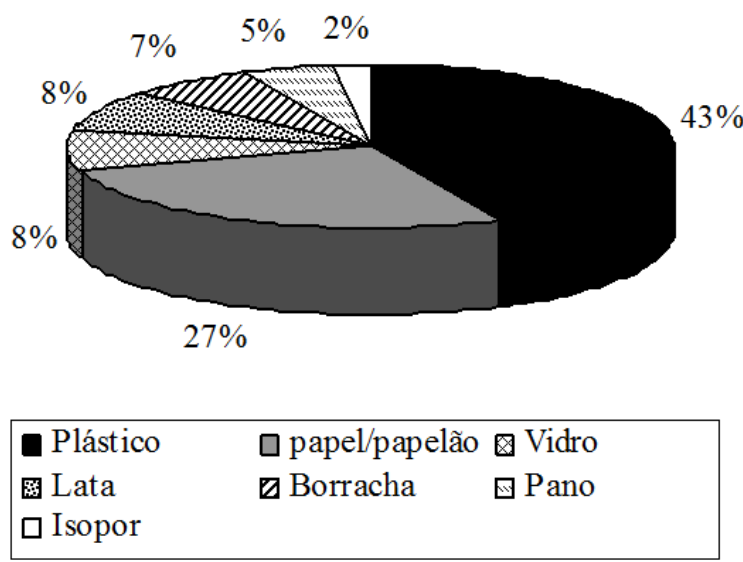

Figura 3. Produção (kg) de lixo orgânico e inorgânico em ambas as amostragens (A) e composição do lixo inorgânico (média das duas coletas) (B).

\section{QUALIDADE DA ÁGUA PARA CONSUMO}

A água subterrânea é de grande importância em termos econômicos e de saúde social para populações urbanas em todo mundo. Não há estatísticas exatas a respeito do volume de água utilizada para abastecimento público proveniente da captação subterrânea, embora algo em torno de $50 \%$ de toda a água urbana consumida no mundo seja captada em poços e/ou fontes (CLARKE et al., 1995).

No entanto, a preocupação com a qualidade da água é um fato recente, pois a maioria das pesquisas desenvolvidas anteriormente, apenas visava o aspecto quantitativo. Entretanto, com o crescimento populacional, acompanhado do desenvolvimento industrial e da super utilização dos recursos hídricos, o fator qualidade passou a ser muito importante (MOTA, 1995). Deste modo, é fundamental que os recursos hídricos apresentem condições físico-químicas adequadas para a utilização dos seres vivos, devendo conter substâncias essenciais à vida e estar isentos de outras substâncias que possam produzir efeitos prejudiciais aos organismos (BRAGA et al., 2003).

Os resultados obtidos referentes às análises dos parâmetros físico-químicos da água, em dois poços de abastecimento da comunidade de Acarajó estão apresentados na tabela 2. 
Tabela 2. Análise físico-química da água em dois poços da comunidade de Acarajó, nos períodos seco e chuvoso.

\begin{tabular}{lccccc}
\hline & & & Poço 1 & & Poço 2 \\
\cline { 2 - 5 } \multicolumn{1}{c}{ Parâmetros } & Valores & & Períod & Períod \\
& ideais* & Períod & o & Períod & o \\
& & o Seco & Chuvos & o Seco & Chuvos \\
& & & & & o \\
\hline Cor real (mg Pt/L e UH) & $<05$ & 50 & 0 & 50 & 0 \\
Cor aparente (mg Pt/L e UH) & $<15$ & 150 & 0 & 220 & 0 \\
Turbidez (UNT) & $<40$ & 0 & 0 & 13,63 & 1,42 \\
Material em suspensão g/L & 0 & 0 & 0 & 5,0014 & 0 \\
pH & $6,0-9,0$ & 5,43 & 5,73 & 4,20 & 4,57 \\
Salinidade & 0 & 0 & 0 & 0 & 0 \\
Temperatura ( ${ }^{\circ} \mathrm{C}$ ) & & & & 0 \\
Ferro dissolvido (mg/L Fe) & 0,300 & 0,150 & 0,00 & 0,037 & 0,08 \\
Coliformes totais (UFC / 100 & & $<3,0$ & 9,2 & 3,6 & $<3,0$ \\
Coliformes fecais (UFC / 100 & & 9,2 & $<3,0$ & 9,2 & $<3,0$ \\
\hline
\end{tabular}

*Valores dos parâmetros físico-químicos e microbiológicos segundo resoluções específicas da ANVISA (2004) do CONAMA (1986, 2000, 2005) e da SVS (2006).

De acordo com a tabela 2, pode ser observado que os valores da cor real e da cor aparente estão acima dos valores máximos permitidos pela legislação, em ambos os pontos analisados durante o período seco. Isto ocorre, provavelmente, devido ao aumento da turbidez, da concentração de material orgânico em suspensão e do aumento da concentração de ferro dissolvido no corpo d’água, durante esse período. No entanto, este acréscimo de material orgânico em suspensão, ferro dissolvido, bem como da turbidez, mesmo apresentando-se mais elevados no período seco, ainda estão dentro dos parâmetros estabelecidos pelas resoluções específicas.

O pH observado apresentou-se levemente ácido, em ambos os pontos e períodos analisados, não sofrendo grandes alterações de um período para outro, estando de acordo com dados obtidos por Walker (1995), em outras regiões da Amazônia, onde comprovou-se que as variações no pH da água independem do regime pluviométrico.

No entanto, cabe ressaltar que a salinidade é um dos parâmetros responsáveis pela acidez de um corpo d’água, mas que no presente estudo este parâmetro obteve valores 0 (zero) em todas as análises, mostrando que a acidez desta água deve estar relacionada à outros fatores. De acordo com Souza e Tundisi (2000), a composição química do corpo d’água varia imensamente e é controlada por uma série de fatores como clima, vegetação, características topográfica e geológica, assim como, por atividades humanas. $\mathrm{Na}$ área estudada, a acidez do solo pode ser um dos fatores que acidifica a água analisada (ver item 4.5.7) 
Os coliformes totais e fecais apresentaram valores elevados, comprometendo a qualidade d'água dessa comunidade, pois em ambos os pontos e períodos analisados, os valores registrados foram acima daqueles toleráveis, segundo as resoluções específicas (ANVISA, 2004 e do CONAMA, 1986, 2000 e 2005). De acordo com a CETESB/SP (1992), a presença de coliformes totais na água indica a possibilidade de poluição fecal desta, uma vez que tais microrganismos podem ser encontrados livremente no ambiente. No entanto, a presença de coliformes fecais determina a origem fecal da contaminação, indicando risco da presença de outros microrganismos patogênicos, tornando a água imprópria para o consumo humano (PELCZAR JUNIOR; CHAN; KRIEG, 1996; BASTOS; ALVES, 2000). Estes resultados estão de acordo com estudos realizados por Glaser (2003), em outras comunidades da Planície Costeira Bragantina, onde se constatou a presença de coliformes totais e fecais na água em um grande número de domicílios e escolas dessas comunidades.

\section{DESMATAMENTO}

De acordo com os resultados obtidos, o extrativismo vegetal (uso de madeira de mangue e de capoeira) é uma prática constante na área da comunidade de Acarajó. Em especial, as três espécies de árvores de mangue existentes na área são Rhizophora mangle L., Laguncularia racemosa e Avicennia germinans, e estão sujeitas à aplicação descontrolada das técnicas de extrativismo.

Pelo menos, 68\% das famílias (casas) pesquisadas declararam que retiram madeira do mangue e/ou capoeira, sendo que destes, $55 \%$ realizam o corte total da árvore, $27 \%$ o corte parcial (somente galhos) e $18 \%$ utilizam outros métodos, como a coleta de galhos e troncos secos. Segundo os moradores, entre os múltiplos usos que os mesmos fazem da madeira coletada destacam-se: o consumo doméstico (85\%), o consumo doméstico e a produção e venda de carvão (12\%), e a produção e venda de carvão (3\%).

No entanto, devido ao fato de que a maioria das moradias desta comunidade possui fogões a lenha, estimase que o percentual de casas que utilizam à madeira de mangue e/ou capoeira como combustível, seja ainda maior. Estudos realizados no México, por Maseral et al. (1997), e em El Salvador por Gammage et al. (2002) mostram que o consumo de lenha para uso doméstico em um contexto sócio-econômico semelhante ao existente na área de estudo revela que pelo menos $90 \%$ destes lares dependem da madeira que é retirada das florestas, para ser usada como combustível doméstico (lenha).

Segundo os moradores de Acarajó, as práticas de retirada de madeira de mangue e/ou capoeira, bem como a produção de carvão são preferencialmente realizadas durante a estação seca. A madeira coletada e o carvão (quando produzido) são estocados para serem utilizados e/ou vendidos (carvão quando for o caso), principalmente durante o período chuvoso, uma vez que nesse período, as práticas de retirada da madeira e da produção de carvão, se tornam mais difíceis de serem realizadas. Para Dahdou-Guebas et al. (2000), a prática da produção e venda de carvão é uma atividade muito comum em populações que vivem nas regiões de manguezal, pois esta se torna uma fonte de renda importante para os habitantes mais pobres dessas áreas.

A prática de corte de árvores de mangue para fins comerciais é outro fator de degradação que vem ocorrendo na área da comunidade. Todavia, este tipo de corte não ocorre de forma explícita pelas pessoas que o praticam, e isso é fácil de ser percebido, pois quando as madeiras estão expostas na rodovia PA-458, geralmente não se localiza o responsável pela retirada, e este fato ocorre por receio de denúncias e punições. Por outro lado, as áreas que estão sendo desmatadas são de difícil acesso. 
Segundo trabalho realizado por Glaser et al. (2003) muitos lenhadores também são catadores de caranguejo e dependem da preservação da área de manguezal. Este fato vem favorecendo a que muitos lenhadores locais estejam trabalhando no corte de mangue em outras comunidades da Planície Costeira Bragantina. A estratégia utilizada para o corte é bastante planejada sendo a prática realizada durante o período da noite, principalmente, nos finais de semana e feriados para diminuir os riscos de serem interceptados por autoridades públicas. A faixa de vegetação localizada próxima às margens do rio são mantidas, para atrasar a detecção da atividade de corte. A rapidez também é considerada essencial, para diminuir o risco de conflitos entre a equipe de corte e os moradores locais.

A derrubada do mangue funciona dentro de uma relação clássica de patrão - cliente (KATON et al., 1998; FOELL et al., 1999; TÊVES, 2000). Após o corte, a madeira é transportada para a cidade, geralmente já tendo seu destino (cliente) certo. Esta é misturada com outras madeiras cortadas "legalmente", com o objetivo de dificultar a identificação, e assim são vendidas para serem utilizadas na construção civil, ou preferencialmente em forma de lenha para olarias e padarias da região.

No entanto, nota-se que, de uma forma geral, a população residente na área de estudo, tem consciência da importância do ecossistema de manguezal ali existente, pois a sua subsistência também depende da extração local e da venda de produtos do mangue em pequena escala, como por exemplo, o caranguejo, e o carvão produzido com a madeira extraída do mangue. Estas técnicas estão relacionadas de maneira clara e complexa às estratégias de sustento das populações mais pobres (GLASER, 2003). Por outro lado, os comunitários vêem o desmatamento do mangue, em escala comercial, como um problema ambiental bastante grave, pois esta degradação pode causar sérios impactos ao ambiente e, por conseqüência, em seu modo de vida, comprometendo até mesmo a sua própria sobrevivência.

Por fim, cabe ressaltar que a ilegalidade torna impossível a pesquisa científica mais aprofundada, bem como a aplicação de técnicas comprovadas de manejo florestal sustentável, como a derrubada direcional, o uso mais complexo das árvores cortadas, coletas rotativas e planejadas, e o replantio adicional. Estes são métodos de manejo florestais apropriados e possíveis de serem aplicados, o que poderia contribuir muito para o aumento da sustentabilidade do corte na área de estudo.

\section{USO DO SOLO PARA PRÁTICA DE AGRICULTURA}

Historicamente, os moradores da comunidade de Acarajó sempre desenvolveram dois tipos de uso do solo para prática da agricultura, sendo o cultivo em terra firme para o plantio de produtos como mandioca/macaxeira (Manihot esculenta), milho (Zea mays), feijão caupi (Vigna unguiculata), etc.; e em áreas de manguezal para o cultivo do arroz (Horyza Sativa). Cabe ressaltar que a atividade de rizicultura desempenhou papel central entre as atividades econômicas da comunidade de Acarajó, onde além de ser a base da alimentação, era também a principal fonte de renda dos moradores desta comunidade (CANELLES, 2001). Atualmente, o arroz passou a ser cultivado apenas para a subsistência, suprindo necessidades de alimentação familiar, como também para a manutenção da tradição local para a realização anual do Festival de Arroz (CANELLES, 2001).

Por outro lado, a agricultura de terra firme está muito presente até os dias atuais, abrangendo várias áreas de terra que são usadas para o cultivo, tornando-se uma das principais formas de subsistências para pelo menos $52 \%$ das pessoas que ali vivem. 
Para o cultivo do solo, os moradores da comunidade de Acarajó realizam a agricultura itinerante, ou seja, um manejo baseado em métodos tradicionais, que consiste na derrubada e queima da capoeira para o preparo da terra (SANCHEZ, 1979; SMITH; BASTOS, 1984; KATO, 1988). Para a implantação das lavouras na área da comunidade, as tarefas são todas realizadas manualmente, com o uso apenas de terçados e enxadas e têm nos membros da família, a principal fonte de mão de obra. Nessas áreas, geralmente, são cultivados feijão, mandioca, milho, entre outras culturas.

Neste sistema após alguns anos de cultivo, o solo é abandonado para a regeneração de uma floresta secundária (capoeira), sendo posteriormente utilizado após vários anos de pousio (descanso do solo) (SANCHEZ, 1976). No presente estudo constatou-se que o pousio, dura em média 5 anos, e após este período, o solo volta a ser usado. De acordo com Smith e Bastos (1984), o sistema de pousio, pela regeneração da floresta, permite uma acumulação de nutrientes na biomassa do solo, ajudando na sua recuperação da fertilidade. No entanto, isso requer um elevado período de tempo, o que segundo Salas e Folster (1976) pode levar até 16 anos para que o solo volte a ter nutrientes equivalentes ao da mata primária.

Segundo mais de $50 \%$ dos agricultores extrativistas, a produtividade do solo tem diminuído muito nos últimos anos, independente do rodízio de uso que é feito entre as áreas cultivadas. Isto tem contribuído para o aumento do uso de fertilizantes e pesticidas nas áreas de cultivo, onde cerca de $30 \%$ dos agricultores já faz uso contínuo destes produtos. Este fato é preocupante, pois o uso excessivo e gradativo de fertilizantes e outros produtos químicos contribuem ainda mais para a degradação do solo, bem como da água. Entre a década de 70 e 90, o uso global de fertilizantes aumentou para uma média anual de 3,5\%, ou seja, mais de 4 milhões de toneladas por ano (FAO, 2001).

A tabela 3 apresenta os resultados obtidos decorrentes da análise química realizada em um Latossolo Amarelo, da comunidade do Acarajó.

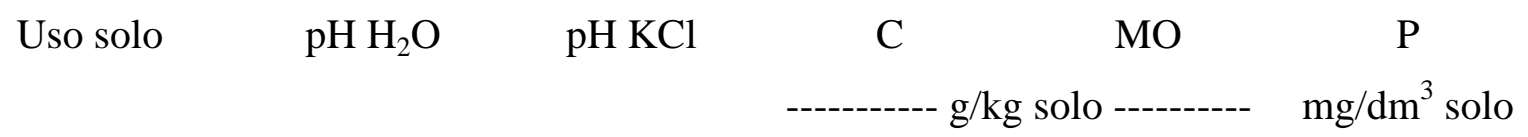

Prof. $0,00-0,05 \mathrm{~m}$ 